\title{
Modelling Conditional Correlations in the Volatility of Asian Rubber Spot and Futures Returns
}

\author{
Tansuchat, R. ${ }^{1}$, T. Khamkaew ${ }^{1}$ and M. McAleer ${ }^{2}$ \\ ${ }^{1}$ Faculty of Economics, Maejo University, Chiang Mai, Thailand \\ ${ }^{2}$ Econometric Institute, Erasmus University Rotterdam, and Department of Applied Economics, National \\ Chung Hsing University, Taiwan \\ Email: roengchaitan@gmail.com
}

\begin{abstract}
At the current time, Asia is the most important market in terms of production for world rubber and consumption. The world prices of rubber are not only subject to the changing in demands, but also to the speculation of the future markets. It is acknowledged that Japan and Singapore are the major futures markets for rubber and Thailand is one of the world's biggest producers of rubber. Since the rubber price is influenced by the external markets, attention should paid in great detail to the relationships between the markets in Thailand, Japan and Singapore. There is a need to empirically examine the natural rubber RSS3 in the market relationship context of these three countries. The analysis is conducted on a variety of multivariate GARCH framework. The results indicate that the constant conditional correlations from CCC models of Bollerslev (1990) are medium and low. The results from VARMA-GARCG of Ling and McAleer (2003) and VARMA-A GARCH of McAleer et al. (2008) suggest the presence of volatility spillovers and asymmetric effects of positive and negative return shocks on the conditional volatility. Fin ally, DCC models of Engle (2002) presents that the conditional correlations can vary dramatically over time. In general, the dynamic volatilities returns in rubber spot and futures returns could be either independent or interdependent over time.
\end{abstract}

Keywords: Rubber futures, Multivariate conditional volatility, Conditional correlation 
$18^{\text {th }}$ World IMA CS / MODSIM Congress, Cairns, Australia 13-17 Ju ly 2009

http://mssanz.org.au/modsim09

\section{Introduction}

Natural rubber is one of the most important agro-based industrial raw materials in the world. Rubber is produced entirely in developing countries and Asian is the largest producing region, accounting for around $96.6 \%$ of output in 2007. Thailand is one of the world's biggest rubber producers. However, their prices are determined in the Singapore and Japanese markets. Providing attention to the factors involved in setting Thailand's rubber prices is quite interesting. According to the relevance of Thailand's rubber price to the Japanese and Singapore markets, the relationship between Thailand spot market and the three majors global rubber futures market; Tokyo Commodity Exchange (TOCOM), Singapore Commodity Exchange and Agriculture Futures Exchange (SICOM) and Osaka Mercantile Exchange (OME), need to be examined. In addition, volatility spillovers s effects will be considered across and within those markets.

Recent works have used the GARCH specification in modeling the volatility spillovers across futures market. The volatility transmission between futures and cash markets had received more attention in the financial economic community. Shocks in one market not only affect price volatility itself, but also on other markets involved. Apergis and Rezitis (2003) investigate volatility spillovers effects across agricultural input prices, agricultural output prices and retail food prices using GARCH models. Feng, et. al (2009) examined the intertemporal information transmission mechanism between the palm oil futures market and the physical cash market in Malaysia.

Despite the well-documented GARCH framework, most of the researches in agricultural futures market are confined to univariate GARCH analysis. According to Chan and McAleer (2003), the univariate GARCH model has two important restrictions: (1) it does not accommodate the asymmetric effects of positive and negative shocks; and (2) it does not permit interdependencies across different assets and/or markets. Modeling volatility through multivariate framework leads to more relevant empirical model than working with separate univariate models in financial markets where its volatilities move together over time across assets and markets.

So far for the agricultural commodity future market, few papers have been devoted to analyzing the empirical evidence of volatility spillovers across futures market and physical cash market in the context of multivariate GARCH approach. For example, Kim and Doucouliagos (2005) examined volatility spillovers effects by fitting a multivariate model to realized volatility and correlation estimates. The dynamic relationships and causations among the volatilities and correlations of three grain futures prices (corn, soybean and wheat) are investigated, by conducting impulse response analys is based on the vector autoregressive model.

Accordingly, the purpose of this paper is to (1) to model the multivariate conditional volatility in the returns on rubber spot and futures price in three major rubber futures markets, namely TOCOM, OME and SICOM and two rubber spot markets, Bangkok and Singapore, using recently developed models of multivariate conditional volatility models, namely the CCC model of Bollerslev (1990), DCC model of Engle (2002), VARMA-GARCH of Ling and McAleer (2003), and VARMA-AGARCH model of McAleer et al. (2008) and (2) to investigate volatility transmission across those markets.

The paper itself is divided into four sections. The second section explains the data employed in the analysis and presents some brief summary statistics. The third section discusses the methodology employed. The results are dealt with in the fourth section. The paper ends with some brief concluding remarks.

\section{Methodol ogy}

This section presents models of the volatility in rubber spot and futures prices returns, namely the CCCMGARCH model of Bollerslev (1990), VARMA-GARCH model of Ling and McAleer (2003), VARMAAGARCH of McAleer et al. (2008) and DCC model of Engle (2002). The typical specification underlying the multivariate conditional mean and conditional variance in returns are given as follow:

$$
\begin{gathered}
y_{t}=E\left(y_{t} \mid F_{t-1}\right)+\varepsilon_{t} \\
\varepsilon_{t}=D_{t} \eta_{t}
\end{gathered}
$$

where $y_{t}=\left(y_{1 t}, \ldots, y_{m t}\right)^{\prime}, \eta_{t}=\left(\eta_{1 t}, \ldots, \eta_{m t}\right)^{\prime}$ is a sequence of independently and identically distributed (iid) random vectors, $F_{t}$ is the past information available to time $t, D_{t}=\operatorname{diag}\left(h_{1}^{1 / 2}, \ldots, h_{m}^{1 / 2}\right)$. The constant conditional correlation (CCC) model of Bollerslev (1990) assumes that the conditional variance for each return, $h_{i t}, i=1, . ., m$, follows a univariate GARCH process, that is 


$$
h_{i t}=\omega_{i}+\sum_{j=1}^{r} \alpha_{i j} \varepsilon_{i, t-j}^{2}+\sum_{j=1}^{s} \beta_{i j} h_{i, t-j}
$$

where $\alpha_{i j}$ and $\beta_{i j}$ represents the $\mathrm{ARCH}$ effect and the GARCH effects, respectively. The conditional correlation matrix of CCC is $\Gamma=E\left(\eta_{t} \eta_{t}^{\prime} \mid F_{t-1}\right)=E\left(\eta_{t} \eta^{\prime}\right)$, where $\Gamma=\left\{\rho_{i t}\right\}$ for $i, j=1, \ldots, m$. From (1), $\varepsilon_{t} \varepsilon_{t}^{\prime}=D_{t} \eta_{t} \eta^{\prime} D_{t}, D_{t}=\left(\operatorname{diag} Q_{t}\right)^{1 / 2}$, and $E\left(\varepsilon_{t} \varepsilon_{t}^{\prime} \mid F_{t-1}\right)=Q_{t}=D_{t} \Gamma D_{t}$, where $Q_{t}$ is the conditional covariance matrix. The conditional correlation matrix is defined as $\Gamma=D_{t}^{-1} Q_{t} D_{t}^{-1}$, and each conditional correlation coefficient is estimated from the standardized residuals in (1) and (2). Therefore, there is no multivariate estimation involved for $\mathrm{CCC}$, except in the calculation of the conditional correlations.

This model assumes independence of the conditional variance across returns. In order to accommodate possible interdependencies, Ling and McAleer (2003) proposed a vector autoregressive moving average (VARMA) specification of the conditional mean in (1) and the following specification for the conditional variance:

$$
H_{t}=W+\sum_{i=1}^{r} A_{i} \vec{\varepsilon}_{t-i}+\sum_{j=1}^{s} B_{j} H_{t-j}
$$

where $H_{t}=\left(h_{1 t}, \ldots, h_{m t}\right)^{\prime}, \vec{\varepsilon}=\left(\varepsilon_{1 t}^{2}, \ldots \varepsilon_{m t}^{2}\right)^{\prime}$, and $W, A_{i}$ for $i=1, . ., r$ and $B_{j}$ for $j=1, . ., s$ are $m \times m$ matrices. As in the univariate GARCH model, VARMA-GARCH assumes that negative and positive shocks have identical impacts on the conditional variance. To separate the asymmetric impacts of the positive and negative shocks, McAleer et al. (2008) proposed the VARMA-AGARCH specification for the conditional variance, namely

$$
H_{t}=W+\sum_{i=1}^{r} A_{i} \vec{\varepsilon}_{t-i}+\sum_{i=1}^{r} C_{i} I_{t-i} \vec{\varepsilon}_{t-i}+\sum_{j=1}^{s} B_{j} H_{t-j}
$$

where $C_{i}$ are $m \times m$ matrices for $i=1, . ., r$, and $I_{t}=\operatorname{diag}\left(I_{1 t}, \ldots, I_{m t}\right)$, where

$$
I_{i t}=\left\{\begin{array}{ll}
0, & \varepsilon_{i t}>0 \\
1, & \varepsilon_{i t} \leq 0
\end{array} .\right.
$$

If $m=1$, (3) collapse to the asymmetric GARCH, or GJR model. Moreover, VARMA-AGARCH reduces to VARMA-GARCH when $C_{i}=0$ for all $i$. If $C_{i}=0$ and $A_{i}$ and $B_{j}$ being diagonal matrices for all $i$ and $j$ then VARMA-AGARCH reduces to CCC-MGARCH. The parameters of model (1)-(4) are obtained by maximum likelihood estimation (MLE) using a joint normal density. When $\eta_{t}$ does not follow a joint multivariate normal distribution, the appropriate estimator is defined as the Quasi-MLE (QMLE).

Unless $\eta_{t}$ is a sequence of i.i.d. random vectors, or alternatively a martingale difference process, the assumption that the conditional correlations are constant may seen unrealistic. In order to make the conditional correlation matrix time-dependent, Engle (2002) proposed a dynamic conditional correlation (DCC) model. The DCC model is defined as:

$$
\begin{gathered}
y_{t} \mid \mathfrak{I}_{t-1} \square\left(0, Q_{t}\right), t=1, \ldots, T \\
Q_{t}=D_{t} \Gamma_{t} D_{t},
\end{gathered}
$$

where $D_{t}=\operatorname{diag}\left(h_{1 t}, \ldots, h_{k t}\right)$ is a diagonal matrix of conditional variance, and $\mathfrak{J}_{t}$ is the information set available to time $t$. The conditional variance, $h_{i t}$, can be defined as a univariate GARCH model as follow:

$$
h_{i t}=\omega_{i}+\sum_{k=1}^{p} \alpha_{i k} \varepsilon_{i, t-k}+\sum_{l=1}^{q} \beta_{i l} h_{i, t-l}
$$

If $\eta_{t}$ is a vector of i.i.d. random variables, with zero mean and unit variance, $Q_{t}$ in (9) is the conditional covariance matrix (after standardization, $\eta_{i t}=y_{i t} / \sqrt{h_{i t}}$ ). The $\eta_{i t}$ are used to estimate the dynamic conditional correlation, as follows: 
Tansuchat et al., Modelling conditional correlations in the volatility of Asia rubber spot and futures returns

$$
\Gamma_{t}=\left\{( \operatorname { d i a g } ( Q _ { t } ) ^ { - 1 / 2 } \} Q _ { t } \left\{\left(\operatorname{diag}\left(Q_{t}\right)^{-1 / 2}\right\},\right.\right.
$$

where the $k \times k$ symmetric positive definite matrix $Q_{t}$ is given by

$$
Q_{t}=\left(1-\theta_{1}-\theta_{2}\right) \bar{Q}+\theta_{1} \eta_{t-1} \eta_{t-1}^{\prime}+\theta_{2} Q_{t-1}
$$

in which $\theta_{1}$ and $\theta_{2}$ are scalar parameters to capture the effect of previous shocks and previous dynamic conditional correlations on current dynamic conditional correlation, and $\alpha$ and $\beta$ are non-negative scalar parameters satisfying $\alpha+\beta<1$. As $Q_{t}$ in is conditional on the vector of standardized residuals, (9) is conditional covariance matrix. $\bar{Q}$ is the $k \times k$ unconditional variance matrix of $\eta_{t}$.

\section{Data}

The multivariate GARCH models are estimated using data on daily closing prices of spot and futures returns and expressed in local currencies for the period 23 September 1994 to 13 March 2009 giving a total of 3,755 observations. All data are obtained form the Reuters. The data set comprises 2 daily RSS3 spot prices, namely RSS3 F.O.B. spot price from Bangkok (TRSS3: Bath $/ \mathrm{kg}$.) and RSS3 Noon spot price from Singapore (SRSS3: Singapore cent $/ \mathrm{kg}$.), and 3 daily RSS3 futures from different futures markets, namely Tokyo Commodity Exchange (TOCOM: Yen/kg.), Osaka Mercantile Exchange (OME: Yen/kg.) and Singapore Commodity Exchange and Agriculture Futures Exchange (SICOM: US cent $/ \mathrm{kg}$ ). Returns of market $i$ at time $t$ are calculated as $r_{i, t}=\log \left(P_{i, t} / P_{i, t-1}\right)$, where $P_{i, t}$ and $P_{i, t-1}$ are the closing prices of spot or futures for days $t$ and $t$-1, respectively. Fig.3. plots the daily of RSS3 spot and futures prices, the patterns in these series are remarkably similar.

\section{Empirical results}

The Augmented Dickey-Fuller (ADF) and the Phillips-Perron (PP) test are used to explore the existence of unit roots in the individual series and available from the authors upon request. Both tests have same the null hypothesis being used to check non-stationary in each time series data. The results show that all returns series are stationary. In order to see whether conditional variances of the return series follow the ARCH process, univariate ARMA-GARCH and ARMA-GJR model will be estimated. Both the ARCH and GARCH estimates are significant of spot and futures returns.

Constant conditional correlations among spot and futures returns from CCC models are summarized in Table 1. Two entries for each pair are their respective estimates and Bollerslev and Wooldridge (1992) robust $t$ ratios. For the five returns, there are 10 conditional correlations, with the highest estimated constant conditional correlation being 0.685 between the standardized shock to the volatilities in the SICOM and TOCOM returns and the lowest being 0.236 between the standardized shocks to the volatilities in the TRSS3 and TOCOM.

Table1 Conditional correlation from CCC models

\begin{tabular}{cccccccccc}
\hline Returns & OME & SICOM & t-ratios & SRSS3 & t-ratios & TOCOM & t-ratios & TRSS3 & t-ratios \\
\hline OME & 1 & $\mathbf{0 . 4 8 3}$ & $\mathbf{( 4 6 . 6 2 )}$ & $\mathbf{0 . 3 9 3}$ & $\mathbf{( 3 0 . 4 7 )}$ & $\mathbf{0 . 6 8 5}$ & $\mathbf{( 1 3 2 . 0 )}$ & $\mathbf{0 . 2 6 2}$ & $\mathbf{( 1 9 . 0 5 )}$ \\
SICOM & 1 & & $\mathbf{0 . 5 2 6}$ & $\mathbf{( 4 7 . 9 8 )}$ & $\mathbf{0 . 5 2 4}$ & $(\mathbf{5 0 . 7 )}$ & $\mathbf{0 . 2 7 5}$ & $\mathbf{( 1 9 . 0 5 )}$ \\
SRSS3 & & & & 1 & & $\mathbf{0 . 4 0 1}$ & $\mathbf{( 3 2 . 2 7 )}$ & $\mathbf{0 . 4 9 1}$ & $\mathbf{( 4 4 . 3 5 )}$ \\
TOCOM & & & & & & 1 & & $\mathbf{0 . 2 3 6}$ & $(\mathbf{1 6 . 1 2 )}$ \\
TRSS3 & & & & & & & & 1 & \\
\hline
\end{tabular}

Notes: (1) The two entries for each parameter are their respective parameter estimates and Bollerslev and Wooldridge (1992) robust $t$-ratios. (2) Entries in bold are significant at the $95 \%$ level.

The DCC estimates of the conditional correlation between the volatilities of spot and futures rubber returns based on estimating univariate $\operatorname{GARCH}(1,1)$ models are given in Table 2. Based on the Bollerslev and Woodridge robust $t$-ratios, the estimated of the two DCC parameters $\left(\hat{\theta}_{1}\right)$ and $\left(\hat{\theta}_{2}\right)$ are statistically significant, except for the short run persistence of shocks on the dynamic correlation $\left(\hat{\theta}_{1}\right)$ of trss 3 ome, trss 3 _tocom and trss3_sicom, where as the every long run persistence to the conditional correlations

being statistically significant close to 0.99 , which makes it clear that the assumption of constant conditional correlation is not supported empirically. The short-run persistence of shocks on the dynamic conditional 
correlation is greatest between the returns in ome tocom being 0.108, whereas the largest long-run persistence of shocks to the conditional correlations is between returns of srss 3 sicom being $0.998=$ $0.996+0.002$. The time-varying conditional correlations between pair of returns are plotted in Fig 4 .

Table 2 Dynamic conditional correlations

\begin{tabular}{ccccc}
\hline Returns & $\hat{\theta}_{1}$ & t-ratios & $\hat{\theta}_{2}$ & t-ratios \\
\hline trss3_srss3 & $\mathbf{0 . 0 1 4}$ & $\mathbf{( 5 . 3 9 4 )}$ & $\mathbf{0 . 9 8 1}$ & $\mathbf{( 2 6 7 . 4 3 2 )}$ \\
trss3_ome & 0.003 & $(0.866)$ & $\mathbf{0 . 9 8 7}$ & $\mathbf{( 4 9 . 2 6 5 )}$ \\
trss3_tocom & 0.003 & $(1.370)$ & $\mathbf{0 . 9 9 1}$ & $\mathbf{( 1 2 5 . 6 9 1 )}$ \\
trss3_sicom & 0.002 & $(1.465)$ & $\mathbf{0 . 9 9 4}$ & $\mathbf{( 2 4 5 . 0 5 0 )}$ \\
srss3_ome & $\mathbf{0 . 0 2 1}$ & $\mathbf{( 4 . 0 3 4 )}$ & $\mathbf{0 . 9 5 8}$ & $\mathbf{( 8 7 . 3 4 9 )}$ \\
srss3_tocom & $\mathbf{0 . 0 2 0}$ & $\mathbf{( 3 . 7 7 6 )}$ & $\mathbf{0 . 9 5 9}$ & $\mathbf{( 8 5 . 9 1 8 )}$ \\
srss3_sicom & $\mathbf{0 . 0 0 2}$ & $\mathbf{( 2 . 4 2 3 )}$ & $\mathbf{0 . 9 9 6}$ & $\mathbf{( 4 9 7 . 7 0 )}$ \\
ome_tocom & $\mathbf{0 . 1 0 8}$ & $\mathbf{( 3 0 . 5 5 8 )}$ & $\mathbf{0 . 8 7 8}$ & $\mathbf{( 2 1 1 . 6 4 0 )}$ \\
ome_sicom & $\mathbf{0 . 0 1 7}$ & $\mathbf{( 7 . 1 3 2 )}$ & $\mathbf{0 . 9 7 8}$ & $\mathbf{( 3 2 8 . 6 5 1 )}$ \\
tocom_sicom & $\mathbf{0 . 0 5 3}$ & $\mathbf{( 1 2 . 4 8 8 )}$ & $\mathbf{0 . 9 3 6}$ & $\mathbf{( 1 8 1 . 2 2 1 )}$ \\
\hline
\end{tabular}

Note: Two entries for each parameter are their respective Bollerslev and Wooldridge (1992) robust $t$ - ratios.
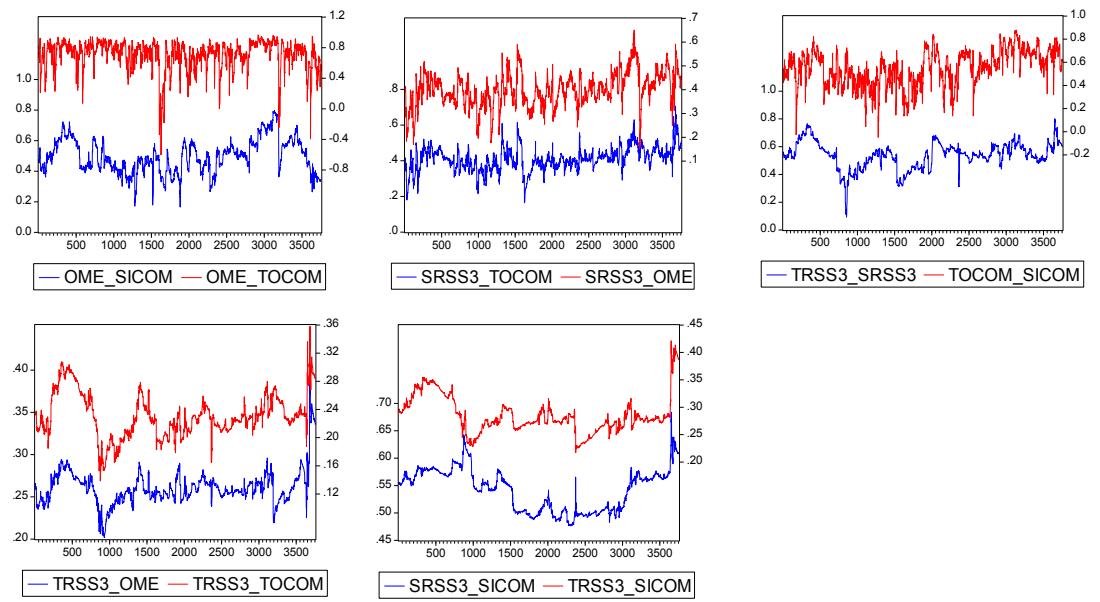

-TRSS3_SRSS3 - TOCOM_SICOM

Fig. 4. Dynamic conditional correlations (DCC) between pair of rubber spot and futures

Finally, the volatility spillovers estimates between the volatilities of spot and futures rubber returns based on estimating VARMA-GARCH and VARMA-AGARCH models are given in Table 3 and 4, respectively. Panel 3a-3j, show that volatility spilloverss of VARMA-GARCH models are evident in 7 to 10 cases, whereas the significant interdependences are only evidence in 3 to 10 cases. Panel $4 \mathrm{a}-4 \mathrm{j}$, present the evidence of volatility spilloverss of VARMA-AGARCH models are 8 to 10 cases, while the significant interdependences are only evidence in 3 to 10 cases. In addition, the estimates of the conditional variance show significant asymmetric effects of positive and negative return shocks on the conditional volatility in all cases, suggesting that VARMA-AGARCH is better to VARMA-GARCH.

\section{Conclusion}

In this paper, we estimated four multivariate conditional volatility models in rubber spot and futures return $\mathrm{s}$ from Asian rubber markets, namely Thailand, Singapore, and Japan, for the period 23 September 1994 to 13 March 2009. All rubber return series were stationary. The constant conditional correlation between spot and futures rubber returns form CCC-GARCH $(1,1)$ were medium and low. The VARMA-GARCH results showed that there were spillover effects between most pair of spot and futures rubber return, and some pair of returns have evidence of interdependence, as well as the result of VARMA-AGARCH. In addition, the statistically significant asymmetric effect of negative and positive shocks on conditional variance suggested that VARMA-AGARCH is better than VARMA-GARCH. The DCC estimates of the conditional correlation between the volatilities of spot and futures returns were statically significant. Therefore, the conditional correlations were dynamic. 
$18^{\text {th }}$ World IMA CS / MODSIM Congress, Cairns, Australia 13-17 Ju ly 2009

http://ms sanz.org.au/modsim09

Table 3 VARMA(1-1)-GARCH(1,1) estimates Panel 3a. VARMA-GARCH: TRSS3 SRSS3

\begin{tabular}{|c|c|c|c|c|c|}
\hline & $\varpi$ & $\alpha_{\text {TRSS3 }}$ & $\alpha_{\text {SRSS3 }}$ & $\beta_{\mathrm{TRSS} 3}$ & $\beta_{\mathrm{SRSS} 3}$ \\
\hline TRSS3 & $\begin{array}{c}0.013 \\
(3.224)\end{array}$ & $\begin{array}{c}0.088 \\
(5.298)\end{array}$ & $\begin{array}{c}\mathbf{0 . 8 0 2} \\
(27.089)\end{array}$ & $\begin{array}{c}0.117 \\
(5.379)\end{array}$ & $\begin{array}{c}-0.025 \\
(-1.554)\end{array}$ \\
\hline SRSS3 & $\begin{array}{c}0.015 \\
(3.860)\end{array}$ & $\begin{array}{c}0.078 \\
(6.106)\end{array}$ & $\begin{array}{c}0.868 \\
(37.473)\end{array}$ & $\begin{array}{c}0.004 \\
(0.200)\end{array}$ & $\begin{array}{c}0.046 \\
(4.737)\end{array}$ \\
\hline \multicolumn{6}{|c|}{ Panel 3b. VARMA-GARCH: OME_TRSS3 } \\
\hline & $\varpi$ & $\alpha_{\mathrm{OME}}$ & $\alpha_{\mathrm{TRSS} 3}$ & $\beta_{\mathrm{OME}}$ & $\beta_{\mathrm{TRSS} 3}$ \\
\hline OME & $\begin{array}{c}0.109 \\
(1.807)\end{array}$ & $\begin{array}{c}0.058 \\
(3.533)\end{array}$ & $\begin{array}{c}0.914 \\
(31.831)\end{array}$ & $\begin{array}{c}0.089 \\
(1.984)\end{array}$ & $\begin{array}{c}-0.048 \\
(-0.843)\end{array}$ \\
\hline TRSS3 & $\begin{array}{c}0.019 \\
(2.693)\end{array}$ & $\begin{array}{c}0.090 \\
(6.716)\end{array}$ & $\begin{array}{c}0.882 \\
(63.377)\end{array}$ & $\begin{array}{r}-0.006 \\
(3.317)\end{array}$ & $\begin{array}{c}0.009 \\
(-2.154)\end{array}$ \\
\hline \multicolumn{6}{|c|}{ Panel 3c. VARMA-GARCH: TRSS3_TOCOM } \\
\hline & $\varpi$ & $\alpha_{\mathrm{TRSS} 3}$ & $\alpha_{\mathrm{TOCOM}}$ & $\beta_{\mathrm{TRSS} 3}$ & $\beta_{\text {тосом }}$ \\
\hline TRSS3 & $\begin{array}{c}0.013 \\
(9.172)\end{array}$ & $\begin{array}{c}\mathbf{0 . 1 0 7} \\
(17.719)\end{array}$ & $\begin{array}{c}0.006 \\
(2.877)\end{array}$ & $\begin{array}{c}0.856 \\
(98.607)\end{array}$ & $\begin{array}{c}0.040 \\
(3.449)\end{array}$ \\
\hline TOCOM & $\begin{array}{c}0.774 \\
(15.620)\end{array}$ & $\begin{array}{c}-0.314 \\
(-10.097)\end{array}$ & $\begin{array}{c}0.265 \\
(25.674)\end{array}$ & $\begin{array}{c}1.650 \\
(8.166)\end{array}$ & $\begin{array}{c}0.514 \\
(33.838)\end{array}$ \\
\hline \multicolumn{6}{|c|}{ Panel 3d. VARMA-GARCH: SICOM_TRSS3 } \\
\hline & $\varpi$ & $\alpha_{\text {SICOM }}$ & $\alpha_{\mathrm{TRSS} 3}$ & $\beta_{\mathrm{SICOM}}$ & $\beta_{\mathrm{TRSS} 3}$ \\
\hline SICOM & $\begin{array}{c}0.032 \\
(4.600)\end{array}$ & $\begin{array}{c}0.081 \\
(6.111)\end{array}$ & $\begin{array}{c}0.880 \\
(44.355)\end{array}$ & $\begin{array}{c}0.060 \\
(3.660)\end{array}$ & $\begin{array}{c}-0.021 \\
(-0.949)\end{array}$ \\
\hline TRSS3 & $\begin{array}{c}0.044 \\
(4.297) \\
\end{array}$ & $\begin{array}{c}0.116 \\
(5.233) \\
\end{array}$ & $\begin{array}{c}0.674 \\
(14.038) \\
\end{array}$ & $\begin{array}{c}-0.030 \\
(-2.487) \\
\end{array}$ & $\begin{array}{c}0.114 \\
(5.694)\end{array}$ \\
\hline \multicolumn{6}{|c|}{ Panel 3e. VARMA-GARCH: OME_SRSS3 } \\
\hline & $\varpi$ & $\alpha_{\mathrm{OME}}$ & $\alpha_{\mathrm{SRSS} 3}$ & $\beta_{\mathrm{OME}}$ & $\beta_{\mathrm{SRSS} 3}$ \\
\hline $\mathrm{OME}$ & $\begin{array}{c}0.623 \\
(3.744) \\
\end{array}$ & $\begin{array}{c}0.121 \\
(4.110) \\
\end{array}$ & $\begin{array}{c}0.667 \\
(8.962)\end{array}$ & $\begin{array}{c}0.276 \\
(1.625) \\
\end{array}$ & $\begin{array}{c}0.065 \\
(0.486)\end{array}$ \\
\hline SRSS3 & $\begin{array}{c}0.021 \\
(4.700)\end{array}$ & $\begin{array}{c}0.097 \\
(8.128)\end{array}$ & $\begin{array}{l}0.886 \\
(69.017) \\
\end{array}$ & $\begin{array}{l}-0.004 \\
(-2.923) \\
\end{array}$ & $\begin{array}{c}0.004 \\
(3.782)\end{array}$ \\
\hline
\end{tabular}

Panel 3f. VARMA-GARCH: SRSS3 TOCOM

\begin{tabular}{|c|c|c|c|c|c|}
\hline & $\varpi$ & $\alpha_{\mathrm{SRSS3}}$ & $\alpha_{\text {тосом }}$ & $\beta_{\mathrm{SRSS} 3}$ & $\beta_{\text {тосом }}$ \\
\hline SRSS3 & $\begin{array}{r}\mathbf{0 . 0 3 3} \\
(7.347) \\
\end{array}$ & \begin{tabular}{|c|}
0.093 \\
$(8.312)$ \\
\end{tabular} & $\begin{array}{c}0.890 \\
(78.160)\end{array}$ & $\begin{array}{c}0.008 \\
(5.703) \\
\end{array}$ & $\begin{array}{r}-0.009 \\
(-6.221) \\
\end{array}$ \\
\hline TOCOM & $\begin{array}{c}0.792 \\
(3.246 \\
\end{array}$ & $\begin{array}{r}0.244 \\
(3.004) \\
\end{array}$ & $\begin{array}{c}0.561 \\
(5.383) \\
\end{array}$ & $\begin{array}{c}0.509 \\
(2.418) \\
\end{array}$ & $\begin{array}{c}0.018 \\
(0.179) \\
\end{array}$ \\
\hline \multicolumn{6}{|c|}{ Panel 4g. VARMA-GARCH: SRSS3_SICOM } \\
\hline & $\varpi$ & $\alpha_{\mathrm{SRSS} 3}$ & $\alpha_{\text {SICOM }}$ & $\beta_{\mathrm{SRSS} 3}$ & $\beta_{\text {SICOM }}$ \\
\hline SR SS3 & $\begin{array}{c}0.041 \\
(1.329) \\
\end{array}$ & $\begin{array}{c}0.022 \\
(0.876) \\
\end{array}$ & $\begin{array}{l}-0.002 \\
(-0.025) \\
\end{array}$ & $\begin{array}{c}0.343 \\
(4.846) \\
\end{array}$ & $\begin{array}{c}0.242 \\
(10.442)\end{array}$ \\
\hline SICOM & $\begin{array}{c}0.030 \\
(4.370)\end{array}$ & $\begin{array}{c}\mathbf{0 . 0 8 6} \\
(\mathbf{5 . 6 0 0 )}\end{array}$ & $\begin{array}{c}0.879 \\
(32.613)\end{array}$ & $\begin{array}{l}-0.018 \\
(2.664)\end{array}$ & $\begin{array}{c}0.049 \\
(-0.635)\end{array}$ \\
\hline
\end{tabular}

Panel 3h. VARMA-GARCH: OME TOCOM

\begin{tabular}{cccccc}
\hline & $\varpi$ & $\alpha_{\text {OME }}$ & $\alpha_{\text {TOCOM }}$ & $\beta_{\text {OME }}$ & $\beta_{\text {TOCOM }}$ \\
\hline OME & $\mathbf{0 . 2 8 4}$ & $\mathbf{0 . 0 4 7}$ & $\mathbf{0 . 9 1 5}$ & $\mathbf{0 . 0 7 5}$ & $\mathbf{- 0 . 0 8 3}$ \\
& $\mathbf{( 4 . 5 4 5 )}$ & $\mathbf{( 2 . 2 8 6 )}$ & $\mathbf{( 2 7 . 9 2 4 )}$ & $\mathbf{( 2 . 6 6 4 )}$ & $\mathbf{( - 2 . 1 3 2 )}$ \\
\hline TOCOM & 0.526 & $\mathbf{0 . 1 8 8}$ & $\mathbf{0 . 2 4 6}$ & $\mathbf{0 . 4 9 2}$ & $\mathbf{0 . 1 3 4}$ \\
& $(1.713)$ & $(\mathbf{2 . 9 9 7 )}$ & $\mathbf{( 2 . 2 3 5 )}$ & $\mathbf{( 2 . 9 9 4 )}$ & $\mathbf{( 2 . 0 2 2 )}$ \\
\hline
\end{tabular}

Panel 3i. VARMA-GARCH: OME_SICOM

\begin{tabular}{cccccc}
\hline & $\varpi$ & $\alpha_{\text {OME }}$ & $\alpha_{\text {SICOM }}$ & $\beta_{\text {OME }}$ & $\beta_{\text {SICOM }}$ \\
\hline OME & $\mathbf{0 . 4 8 9}$ & $\mathbf{0 . 1 0 8}$ & $\mathbf{0 . 6 9 8}$ & 0.170 & 0.088 \\
& $\mathbf{( 3 . 5 1 8 )}$ & $\mathbf{( 3 . 4 1 6 )}$ & $\mathbf{( 9 . 8 9 6 )}$ & $(1.421)$ & $(0.814)$ \\
\hline SICOM & $\mathbf{0 . 0 3 6}$ & $\mathbf{0 . 0 9 9}$ & $\mathbf{0 . 8 7 9}$ & -0.004 & $\mathbf{0 . 0 0 6}$ \\
& $\mathbf{( 4 . 6 0 6 )}$ & $\mathbf{( 7 . 0 3 8 )}$ & $\mathbf{( 5 5 . 1 0 6 )}$ & $(-1.337)$ & $\mathbf{( 2 . 0 9 6 )}$
\end{tabular}

Panel 3j. VARMA-GARCH: SICOM TOCOM

\begin{tabular}{cccccc}
\hline & $\varpi$ & $\alpha_{\text {SICOM }}$ & $\alpha_{\text {ENI }}$ & $\beta_{\text {SICOM }}$ & $\beta_{\text {ENI }}$ \\
\hline SICOM & $\mathbf{0 . 0 3 6}$ & $\mathbf{0 . 1 0 8}$ & $\mathbf{0 . 8 7 5}$ & 0.001 & -0.002 \\
& $\mathbf{( 4 . 5 1 8 )}$ & $\mathbf{( 7 . 2 4 8 )}$ & $\mathbf{( 5 5 . 7 7 7 )}$ & $(1.105)$ & $(-1.113)$ \\
\hline TOCOM & $\mathbf{0 . 8 1 7}$ & $\mathbf{0 . 2 4 1}$ & $\mathbf{0 . 5 4 6}$ & 0.219 & 0.181 \\
& $\mathbf{( 3 . 0 8 3 )}$ & $\mathbf{( 2 . 6 5 4 )}$ & $\mathbf{( 4 . 5 4 4 )}$ & $(1.270)$ & $(2.005)$ \\
\hline
\end{tabular}
$\begin{array}{lllll}\mathbf{( 3 . 0 8 3 )} & \mathbf{( 2 . 6 5 4 )} & \mathbf{( 4 . 5 4 4 )} & (1.270) & (2.005)\end{array}$

ratios. (2) Entries in bold are significant at the $95 \%$ level.

Table 4 VARMA(1-1)-AGARCH(1,1) estimates Panel 4a. VARMA-AGARCH: SRSS3 TRSS3

\begin{tabular}{ccccccc}
\hline & $\varpi$ & $\alpha_{\text {TRSS } 3}$ & $\alpha_{\text {SRSS } 3}$ & $\gamma$ & $\beta_{\text {TRSS } 3}$ & $\beta_{\text {SRSS } 3}$ \\
\hline SRSS3 & $\mathbf{0 . 0 1 5}$ & $\mathbf{0 . 0 8 7}$ & -0.019 & $\mathbf{0 . 8 7 1}$ & $\mathbf{0 . 0 4 8}$ & 0.002 \\
& $\mathbf{( 3 . 9 4 2 )}$ & $\mathbf{( 5 . 2 2 5 )}$ & $(-0.979)$ & $\mathbf{( 3 8 . 5 0 0 )}$ & $\mathbf{( 4 . 8 2 7 )}$ & $(0.080)$ \\
\hline TRSS3 & $\mathbf{0 . 0 1 3}$ & $\mathbf{0 . 0 9 4}$ & -0.012 & $\mathbf{0 . 8 0 2}$ & $\mathbf{- 0 . 0 2 6}$ & 0.118 \\
& $(\mathbf{3 . 2 2 0})$ & $\mathbf{( 4 . 5 4 2 )}$ & $(-0.376)$ & $(\mathbf{2 6 . 6 0 5})$ & $\mathbf{( - 1 . 5 4 1 )}$ & $(5.458)$ \\
\hline \multicolumn{6}{c}{ Panel 4b. VARMA-AGARCH: OME_TRSS3 } &
\end{tabular}

\begin{tabular}{ccccccc}
\hline & $\varpi$ & $\alpha_{\mathrm{OME}}$ & $\alpha_{\mathrm{TRSS} 3}$ & $\gamma$ & $\beta_{\mathrm{OME}}$ & $\beta_{\mathrm{TRSS} 3}$ \\
\hline OME & 0.112 & $\mathbf{0 . 0 5 4}$ & 0.008 & $\mathbf{0 . 9 1 2}$ & $\mathbf{0 . 0 9 0}$ & -0.047 \\
& $(1.871)$ & $\mathbf{( 2 . 0 9 9 )}$ & $(0.262)$ & $\mathbf{( 3 0 . 8 6 1 )}$ & $\mathbf{( 1 . 9 7 2 )}$ & $(-0.775)$ \\
\hline TRSS3 & $\mathbf{0 . 0 1 9}$ & $\mathbf{0 . 1 0 0}$ & -0.024 & $\mathbf{0 . 8 8 7}$ & $\mathbf{- 0 . 0 0 6}$ & $\mathbf{0 . 0 0 8}$ \\
& $(\mathbf{2 . 6 9 5 )}$ & $\mathbf{( 4 . 6 6 7 )}$ & $(-0.809)$ & $\mathbf{( 6 6 . 2 0 5 )}$ & $\mathbf{( - 2 . 2 6 4 )}$ & $\mathbf{( 3 . 4 0 5 )}$ \\
\hline \multicolumn{7}{c}{ Panel 4c. VARMA-AGARCH: TOCOM TRSS3 }
\end{tabular}

Panel 4c. VARMA-AGARCH: TOCOM TRSS3

\begin{tabular}{cccccc}
$\varpi$ & $\alpha_{\text {TRSS3 }}$ & $\alpha_{\text {TOCOM }}$ & $\gamma$ & $\beta_{\text {TRSS3 }}$ & $\beta_{\text {TOCOM }}$ \\
\hline
\end{tabular}

\begin{tabular}{llllll}
\hline TOCOM 0.823 & $\mathbf{0 . 2 7 4}$ & -0.056 & $\mathbf{0 . 5 8 4}$ & 0.056 & $\mathbf{0 . 3 5 7}$
\end{tabular} \begin{tabular}{llllll}
$\mathbf{( 3 . 3 6 0 )}$ & $\mathbf{( 2 . 1 8 0 )}$ & $(-0.494)$ & $\mathbf{( 5 . 9 3 4 )}$ & $(0.767)$ & $\mathbf{( 2 . 0 0 1 )}$ \\
\hline
\end{tabular}

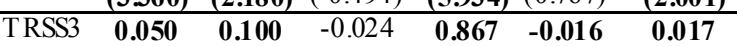
$\begin{array}{lllll}(5.726) & (4.831) & (-0.787) & (61.334)(-4.574) & (4.809)\end{array}$

Panel 4d. VARMA-AGARCH: SICOM TRSS3

\begin{tabular}{|c|c|c|c|c|c|c|}
\hline & $\varpi$ & $\alpha_{\text {SICOM }}$ & $\alpha_{\mathrm{TRSS} 3}$ & $\gamma$ & $\beta_{\text {SICOM }}$ & $\beta_{\mathrm{TRSS} 3}$ \\
\hline$\overline{\text { SICOM }}$ & $\begin{array}{c}0.032 \\
(4.636)\end{array}$ & $\begin{array}{c}0.084 \\
(5.053)\end{array}$ & $\begin{array}{c}-0.008 \\
(-0.382)\end{array}$ & $\begin{array}{c}0.883 \\
(44.908)\end{array}$ & $\begin{array}{c}0.062 \\
(3.767)\end{array}$ & $\begin{array}{c}-0.022 \\
(-1.009)\end{array}$ \\
\hline TRSS3 & $\begin{array}{c}0.045 \\
(4.291) \\
\end{array}$ & $\begin{array}{c}0.101 \\
(3.978)\end{array}$ & $\begin{array}{c}0.032 \\
(0.792) \\
\end{array}$ & $\begin{array}{c}0.675 \\
(14.244)\end{array}$ & $\begin{array}{c}-0.030 \\
(-2.498) \\
\end{array}$ & $\begin{array}{c}0.114 \\
(5.737)\end{array}$ \\
\hline
\end{tabular}

\section{Panel 4e. VARMA-AGARCH: OME SRSS3}

\begin{tabular}{ccccccc}
\hline & $\varpi$ & $\alpha_{\text {OME }}$ & $\alpha_{\text {SRSS3 }}$ & $\gamma$ & $\beta_{\text {OME }}$ & $\beta_{\text {SRSS3 }}$ \\
\hline OME & $\mathbf{0 . 6 2 9}$ & $\mathbf{0 . 1 0 8}$ & 0.030 & $\mathbf{0 . 6 6 4}$ & 0.279 & 0.068
\end{tabular}

$\begin{array}{llllll}\mathbf{( 3 . 8 3 3 )} & \mathbf{( 2 . 6 0 3 )} & (0.596) & \mathbf{( 9 . 0 1 8 )} & (1.650) & (0.497)\end{array}$

\begin{tabular}{lllllll}
\hline SRSS3 & 0.021 & $\mathbf{0 . 1 0 5}$ & -0.016 & $\mathbf{0 . 8 8 7}$ & $\mathbf{- 0 . 0 0 5}$ & $\mathbf{0 . 0 0 5}$
\end{tabular}

$\begin{array}{llll}\text { (4.701) (6.566) }(-0.708) & \mathbf{( 7 0 . 4 2 3 )} & \mathbf{( - 2 . 9 6 7 )} & \mathbf{( 3 . 7 3 1 )}\end{array}$
Panel 4f. VARMA-AGARCH: SRSS3 TOCOM

\begin{tabular}{ccccccc}
\hline & $\varpi$ & $\alpha_{\text {SRS } 3}$ & $\alpha_{\text {TOCOM }}$ & $\gamma$ & $\beta_{\text {SRSS } 3}$ & $\beta_{\text {ТОСО }}$ \\
\hline SRSS3 & $\mathbf{0 . 0 3 2}$ & $\mathbf{0 . 1 0 5}$ & -0.011 & $\mathbf{0 . 8 8 2}$ & $\mathbf{0 . 0 0 7}$ & $\mathbf{- 0 . 0 0 8}$ \\
& $\mathbf{( 5 . 6 1 4 )}$ & $\mathbf{( 6 . 4 1 4 )}$ & $(-0.461)$ & $\mathbf{( 7 1 . 4 9 8 )}$ & $\mathbf{( 4 . 7 1 0 )}$ & $\mathbf{( - 4 . 5 4 9 )}$ \\
\hline TOCOM & $\mathbf{0 . 7 9 3}$ & $\mathbf{0 . 2 7 6}$ & -0.068 & $\mathbf{0 . 5 5 9}$ & $\mathbf{0 . 5 2 6}$ & 0.022 \\
& $(\mathbf{3 . 2 4 2})$ & $(\mathbf{2 . 1 2 8})$ & $(-0.591)$ & $\mathbf{( 5 . 3 1 6 )}$ & $\mathbf{( 2 . 4 3 4 )}$ & $(0.223)$ \\
\hline
\end{tabular}

Panel 4g. VARMA-AGARCH: SICOM_SRSS3

\begin{tabular}{ccccccc}
\hline & $\varpi$ & $\alpha_{\text {SRSS } 3}$ & $\alpha_{\text {SICOM }}$ & $\gamma$ & $\beta_{\text {SRSS } 3}$ & $\beta_{\text {SICOM }}$ \\
\hline SICOM & $\mathbf{0 . 0 3 1}$ & $\mathbf{0 . 0 8 4}$ & 0.005 & $\mathbf{0 . 8 7 9}$ & $\mathbf{0 . 0 5 0}$ & -0.018 \\
& $\mathbf{( 4 . 3 6 2 )}$ & $\mathbf{( 4 . 9 3 2 )}$ & $(0.202)$ & $\mathbf{( 3 2 . 4 9 3 )}$ & $\mathbf{( 2 . 6 3 0 )}$ & $(-0.621)$ \\
\hline SRSS3 & 0.042 & 0.031 & -0.022 & 0.004 & $\mathbf{0 . 3 3 8}$ & $\mathbf{0 . 2 4 2}$ \\
& $(1.386)$ & $(0.875)$ & $(-0.602)$ & $(0.059)$ & $\mathbf{( 4 . 8 1 1 )}$ & $\mathbf{( 1 0 . 4 4 9 )}$ \\
\hline
\end{tabular}

Panel 4h. VARMA-AGARCH: OME TOCOM

\begin{tabular}{|c|c|c|c|c|c|c|}
\hline & $\varpi$ & $\alpha_{\mathrm{OME}}$ & $\alpha_{\text {тосом }}$ & $\gamma$ & $\beta_{\mathrm{OME}}$ & $\beta_{\text {тосом }}$ \\
\hline$\overline{\mathrm{OME}}$ & $\begin{array}{c}0.292 \\
(4.826)\end{array}$ & $\begin{array}{c}0.041 \\
(2.089)\end{array}$ & $\begin{array}{c}0.012 \\
(0.455)\end{array}$ & $\begin{array}{c}0.914 \\
(29.174)\end{array}$ & $\begin{array}{c}0.076 \\
(2.769) \\
\end{array}$ & $\begin{array}{r}-0.085 \\
(-2.277) \\
\end{array}$ \\
\hline$\overline{\mathrm{TOCO}}$ & $\begin{array}{r}0.513 \\
(1.686)\end{array}$ & $\begin{array}{c}0.233 \\
(2.454)\end{array}$ & $\begin{array}{c}-0.090 \\
(-0.924)\end{array}$ & $\begin{array}{c}0.223 \\
(2.047)\end{array}$ & $\begin{array}{c}0.524 \\
(3.208)\end{array}$ & $\begin{array}{l}0.137 \\
(2.100)\end{array}$ \\
\hline
\end{tabular}
Panel 4i. VARMA-GARCH: OME SICOM

\begin{tabular}{ccccc}
$\alpha_{\mathrm{OME}}$ & $\alpha_{\mathrm{SICOM}}$ & $\gamma$ & $\beta_{\mathrm{OME}}$ & $\beta_{\mathrm{SICOM}}$ \\
\hline
\end{tabular}

\begin{tabular}{lllllll}
\hline OME & $\mathbf{0 . 4 8 3}$ & $\mathbf{0 . 0 9 2}$ & 0.032 & $\mathbf{0 . 6 9 8}$ & 0.168 & 0.093
\end{tabular} \begin{tabular}{lllllll}
$\mathbf{( 3 . 6 1 0 )}$ & $\mathbf{( 2 . 1 0 1 )}$ & $(0.660)$ & $\mathbf{( 1 0 . 2 7 6})$ & $(1.414)$ & $(0.843)$ \\
\hline
\end{tabular}

\begin{tabular}{lllllll}
\hline SICOM & $\mathbf{0 . 0 3 6}$ & $\mathbf{0 . 1 0 0}$ & -0.002 & $\mathbf{0 . 8 7 9}$ & -0.005 & $\mathbf{0 . 0 0 6}$
\end{tabular} $\begin{array}{llllll}\text { (4.603) } & \text { (6.062) } & (-0.082) & (\mathbf{5 5 . 1 4 6}) & (-1.341) & \mathbf{( 2 . 1 0 1 )}\end{array}$

Panel 4j. VARMA-AGARCH: SICOM_TOCOM

\begin{tabular}{ccccccc}
\hline & $\varpi$ & $\alpha_{\text {SICOM }}$ & $\alpha_{\text {ENI }}$ & $\gamma$ & $\beta_{\text {SICOM }}$ & $\beta_{\text {ENI }}$ \\
\hline SICOM & $\mathbf{0 . 0 3 7}$ & $\mathbf{0 . 1 0 7}$ & 0.003 & $\mathbf{0 . 8 7 4}$ & 0.001 & -0.002 \\
& $\mathbf{( 4 . 5 1 4 )}$ & $\mathbf{( 6 . 1 5 7 )}$ & $(0.125)$ & $\mathbf{( 5 5 . 5 4 8 )}$ & $(1.084)$ & $(-1.106)$ \\
\hline TOCOM & $\mathbf{0 . 8 2 6}$ & 0.280 & -0.083 & $\mathbf{0 . 5 4 1}$ & 0.234 & $\mathbf{0 . 1 8 9}$ \\
& $\mathbf{( 3 . 0 9 8 )}$ & $(1.918)$ & $(-0.652)$ & $\mathbf{( 4 . 3 7 4 )}$ & $(1.247)$ & $\mathbf{( 2 . 0 4 7 )}$ \\
\hline
\end{tabular}

Notes: (1) The two entries for each parameter are their respective parameter est imates and Bollerslev and Wooldridge (1992) robust $t$ ratios. (2) Entries in bold are significant at the $95 \%$ level. 


\section{ACKNOWLEDGMENTS}

The authors wish to thank Felix Chan and Abdul Hakim for the computer programs. The first author acknowledges the financial support of Faculty of Econo mics, Maejo University.

\section{REF ERENCES}

Apergis, N. and Rezitis, A. (2003), Food price volatility and macroeconomic factor volatility: "heat waves" or "meteor showers"?. Applied Economics Letters, Taylor and Francis Journals, 10(3), 155-160.

Bollerslev, T. (1990), Modelling the coherence in short-run nominal exchange rate: A multivariate generalized ARCH approach. Review of Economics and Statistics, 72, 498-505.

Bollerslev, T. and Wooldridge, J. (1992). Quasi-maximum likelihood estimation and inference in dynamic models with time-varying covariances. Econometric Reviews, 11, 143-172.

Chan, F. and McAleer, M. (2003), Modelling multivariate asymmetric financial volatility, MODSIM 2007 International Congress on Modelling and Simulation. Modelling and Simulation Society of Australia and New Zealand, July 2003, pp. 74-80.

de Veiga, B. and McAleer, M. (2004), Testing multivariate volatility and spillover effects in financial markets, in C. Pahl-Wostl (ed.), The International Environmental Modelling and Software Society Conference, Osnabruck, Germany, June 2004, Conference prodeedings.

Engle, R. F. (2002), Dynamic conditional correlation: A simple class of multivariate generalized autoregressive conditional heteroskedasticity models. Journal of Business and Economic Statistics, 20, 339-350.

Feng, S; Lin, S; Ho, D. (2003), Spillover Effects in the Malaysian Palm Oil Futures and Cash Markets. Malaysian Journal of Economic Studies, Jun-Dec 2003.

Kim, J. and Doucouliagos, H. (2005), "Realized Volatility and Correlation in Grain Futures Markets: Testing for Spill-Over Effects," Monash Econometrics and Business Statistics Working Papers 22/05, Monash University, Austrilia.

Ling, S. and McAleer, M. (2003), Asymptotic theory for a vector ARMA-GARCH model. Econometric Theory, 19, 278-308.

McAleer, M. (2005), Automated inference and learning in modeling financial volatility. Econometric Theory, 21, 232-261.

McAleer, M., Hoti, S. and Chan, F. (2009). Structure and asymptotic theory for multivariate asymmetric conditional volatility. Econometric Reviews, 28, 422-440. 